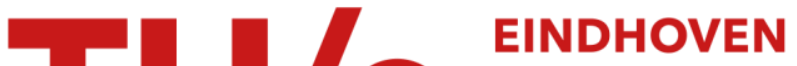 UNIVERSITY OF TECHNOLOGY
}

\section{RF characterization and analytical modelling of through silicon vias and coplanar waveguides for 3D integration}

\section{Citation for published version (APA):}

Lamy, Y., Jinesh, K. B., Roozeboom, F., Gravesteijn, D. J., \& Besling, W. F. A. (2010). RF characterization and analytical modelling of through silicon vias and coplanar waveguides for 3D integration. IEEE Transactions on Advanced Packaging, 33(4), 1072-1079. https://doi.org/10.1109/TADVP.2010.2046166

DOI:

10.1109/TADVP.2010.2046166

Document status and date:

Published: 01/01/2010

\section{Document Version:}

Publisher's PDF, also known as Version of Record (includes final page, issue and volume numbers)

\section{Please check the document version of this publication:}

- A submitted manuscript is the version of the article upon submission and before peer-review. There can be important differences between the submitted version and the official published version of record. People interested in the research are advised to contact the author for the final version of the publication, or visit the $\mathrm{DOI}$ to the publisher's website.

- The final author version and the galley proof are versions of the publication after peer review.

- The final published version features the final layout of the paper including the volume, issue and page numbers.

Link to publication

\section{General rights}

Copyright and moral rights for the publications made accessible in the public portal are retained by the authors and/or other copyright owners and it is a condition of accessing publications that users recognise and abide by the legal requirements associated with these rights.

- Users may download and print one copy of any publication from the public portal for the purpose of private study or research.

- You may not further distribute the material or use it for any profit-making activity or commercial gain

- You may freely distribute the URL identifying the publication in the public portal.

If the publication is distributed under the terms of Article 25fa of the Dutch Copyright Act, indicated by the "Taverne" license above, please follow below link for the End User Agreement:

www.tue.nl/taverne

Take down policy

If you believe that this document breaches copyright please contact us at:

openaccess@tue.nl

providing details and we will investigate your claim. 


\title{
RF Characterization and Analytical Modelling of Through Silicon Vias and Coplanar Waveguides for 3D Integration
}

\author{
Yann P. R. Lamy, K. B. Jinesh, Fred Roozeboom, Dirk J. Gravesteijn, and Wim F. A. Besling
}

\begin{abstract}
High-aspect ratio (12.5) through silicon vias (TSV) made in a silicon interposer have been electrically characterized in the direct current (dc) and microwave regimes for 3D interconnect applications. The vias were micro-machined in silicon, insulated, and filled with copper employing a bottom-up copper electroplating technique in a "via-first" approach. DC via resistance measurements show good agreement with the theoretical expected value $(\sim 16 \mathrm{~m} \Omega)$. Radio-frequency $(\mathrm{RF})$ measurements up to $50 \mathrm{GHz}$ have been performed on coplanar waveguides located on the back-side of the wafers and connected to the front-side with TSVs. The $S$-parameters indicate clearly the beneficial impact of double sided ground planes of the RF signals. The via resistance extracted from impedance measurements is in good agreement with de values, while the inductance $(53 \mathrm{pH})$ and capacitance $(2.4$ pF) of the TSV are much lower than conventional wire bonding, which makes the use of TSV very promising for 3D integration. An advanced analytical model is proposed for the interconnect system with vias and lines and shows very good agreement with the experimental data with a limited number of fitting parameters. This work gives a proof of concept for high aspect ratio TSV manufacturing and new insights to improve 3D interconnect modeling for systems-in-package applications in the microwave regime.
\end{abstract}

Index Terms-Radio-frequency (RF) characterisation, RF modeling, Si interposer, three-dimensional interconnects, through silicon via, through-wafer interconnect, TSV, vias.

\section{INTRODUCTION}

$\mathbf{T}$ HROUGH-SILICON-VIAs (TSVs) are of increasing interest for 3D integrated circuit technology as they appear to be attractive candidates to mitigate issues such as $R C$ delay, thermal heating, and power consumption of conventional 2D integrated circuits (ICs). Moreover, TSVs enable heterogeneous integration into advanced system-in-package products which enable novel "More than Moore" applications. In the near future, several new multifunctional components [e.g., sensors and actuators, MEMS, passives for dc-dc converters, radio-frequency (RF)] should be combined in a compact packages [1], [2]. Lots of architectures have been proposed for these devices

Manuscript received July 28, 2009; revised January 14, 2010 and March 11, 2010; accepted March 12, 2010. First published April 08, 2010; current version published January 07, 2011. This work was supported by Senter-Novem, an agency of The Netherlands Ministry of Economic Affairs ("Innovia" Project No. IS 044041).

The authors are with NXP Semiconductors Research, 5656 AE, Eindhoven, The Netherlands (e-mail: yann.lamy@cea.fr).

Color versions of one or more of the figures in this paper are available online at http://ieeexplore.ieee.org.

Digital Object Identifier 10.1109/TADVP.2010.2046166
[3], [4] but whatever the integration technique (i.e., via last, via first...) the electrical behavior of the 3D interconnect remains a key point as it has to transmit a wide range of different signals varying from analog to digital and RF. According to these requirements, it is mandatory to evaluate static TSV electrical behavior and as function of frequency. However, only a few papers in literature describe the RF electrical behavior of TSVs with front and back-side interconnects [5]-[8]. In addition, the RF data are not always linked to the dc behavior and other via properties. The RF characterization is either done on one-port reflective RF structures ([5], [6]), or on low aspect ratio ( 5) vias ([7], [8]). In terms of modelling, the existing papers on TSV simulations are using complicated numerical techniques like finite element methods, with no clear links to the processing and the real measurements [7], [8]. This limits the use of the simulations significantly. In addition, the impact of grounding in coplanar lines coupled with TSVs has not been investigated in details so far.

In this work, we combine a fabrication method for high aspect ratio TSVs in a silicon interposer with in-depth dc and RF characterizations and modelling. The vias are filled with copper by means of copper electroplating in a "via-first"-like integration approach. The bottom-up plating approach ([5], [6]) has the main advantage to circumvent the lining/seeding limitation problems for high-aspect ratio vias because of the very poor step coverage standard deposition tool [9], [10]. The TSVs are coupled to standard coplanar waveguides (CPW) with different line lengths on the back-side of the wafer to allow in-depth RF analysis. This work demonstrates not only the realization of a silicon interposer but also allows realistic data extraction from RF measurements up to $50 \mathrm{GHz}$. From these results, an advanced electrical model for TSVs has been developed, which is very useful to interpret electrical data and to optimize layout and 3D integration for all kinds of system-in package applications in the microwave regime such as interconnecting active dies with passives and MEMS components [5], [11].

\section{WAFER LAYOUT AND FABRICATION TECHNOLOGY}

For complete electrical characterization, dc and RF device modules have been designed on the same die. The process flow is described in Fig. 1. Fabrication started from one-side polished 6-in wafers. We have chosen low resistivity $(\sim 0.01 \Omega . \mathrm{cm})$ wafers since very often a Si interposer has high doping levels for the devices. We mimic here a worse case scenario. The 20- $\mu \mathrm{m}$ -diameter vias were etched in a STS DRIE etcher with inductively coupled plasma, using a typical Bosch etch process to 


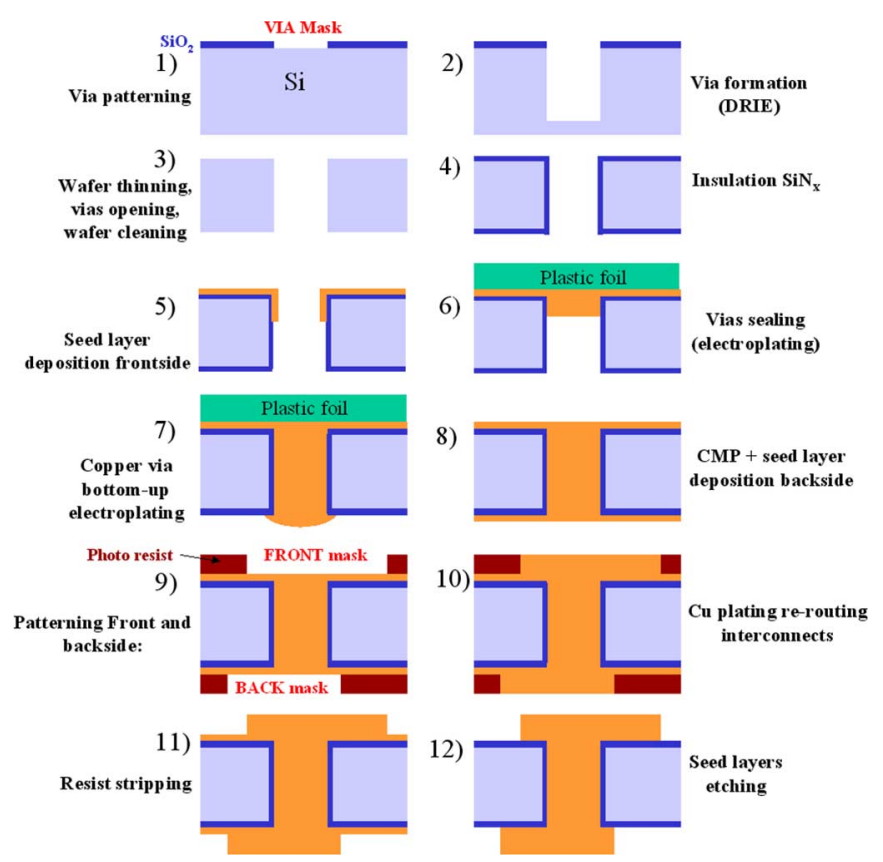

Fig. 1. Fabrication process flow for TSV interposer employing bottom-up electroplating.

achieve vertical sidewalls [2], [12]. A 2.5- $\mu \mathrm{m}$ PECVD $\mathrm{SiO}_{2}$ layer was used as hard mask. The wafer thickness was thinned down to $250 \mu \mathrm{m}$, leading to vias with an aspect ratio (AR) of 12.5. The via insulation is formed with a $500 \mathrm{~nm} \mathrm{SiN}_{\mathrm{x}}$ liner deposited with low pressure chemical vapor deposition to avoid $\mathrm{Cu}$ diffusion into the silicon. A 200-nm PVD Ti/Cu thin film has been deposited on the front-side as seed layer for the $\mathrm{Cu}$ sealing process. The bottom-up via dc electroplating have been carried out similar to techniques used by other groups [5], [6], [10], [12]. Prior to $\mathrm{Cu}$ plating, a plastic foil has been applied on the front-side to prevent the overgrowth of $\mathrm{Cu}$ and to enhance the sealing of vias. After filling a $\sim 4-\mu \mathrm{m}$-thick interconnect on the front and back-side of the wafer has been deposited with $\mathrm{Cu}$ electroplating through a negative photoresist. This subsequent $\mathrm{Cu}$ plating compensates for the possible nonuniform via fill after the primary bottom-up plating, or small recessions that occur on the front-side due to the via sealing. This reinforces the electrical contact between the metal layer and the vias, and level off the discrepancies between vias in terms of filling.

Fig. 2 shows scanning electron microscope (SEM) and optical pictures of the electroplated TSVs with front and back-side interconnects. They show vias uniformly filled with copper in two different areas. The top part shows uniform sealing without voids. Despite a small recession at the bottom, there is a good connection of the via with the bottom-side interconnects.

\section{DC ElECTRICAL MEASUREMENTS}

The sheet resistances $R_{\text {sheet }}=R_{\text {meas }} \times \pi / \ln (2)$ of the plated copper of front and back-side interconnects are extracted from Van der Pauw structures [14]. The resistivity of the plated copper on the front and back-side $(\rho=2.0 \mu \Omega \cdot \mathrm{cm})$ is close to the bulk resistivity of copper $(\rho=1.8 \mu \Omega \cdot \mathrm{cm})$. The small

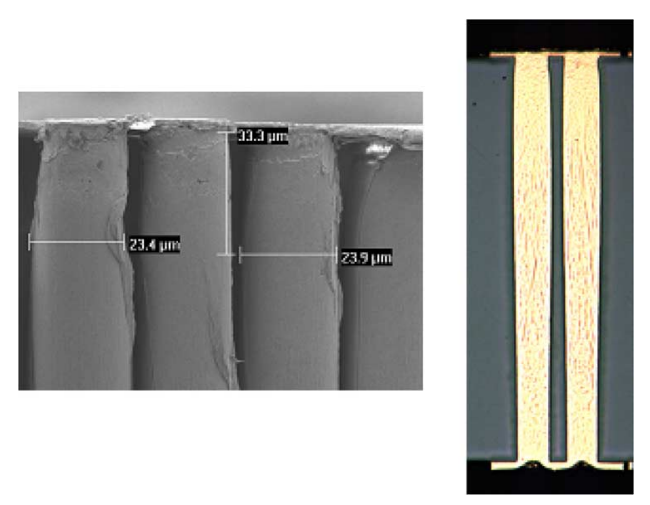

Fig. 2. SEM image of Cu plated vias (left) and optical microscope image of polished cross section of filled via (right).
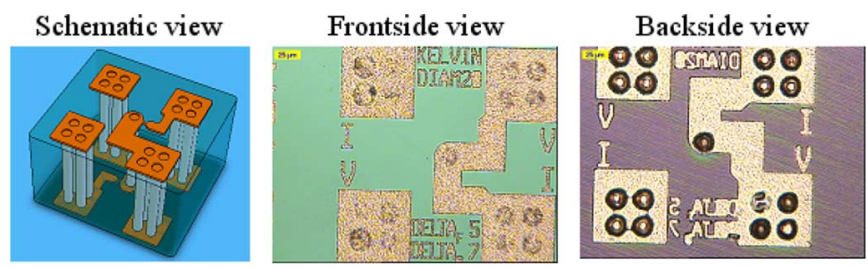

Fig. 3. Schematic drawing and final front and back-side metal patterning for Kelvin structure.

difference could be due to the fact that no anneal has been performed and therefore the grain size is somewhat smaller and less well controlled than after annealing. Individual TSV resistance data were obtained from Kelvin structures using four point probe measurements [14], [15]. A schematic drawing and pictures of the Kelvin structures are shown in Fig. 3. The front-toback electrical connection is made by four TSVs in parallel to contact the back-side electrical pads. With this geometry, only the central single via is probed, excluding the front and back interconnect resistance contributions. The median measured resistance of 250 individual vias is $15.3 \mathrm{~m} \Omega$. This corresponds well to the expected via resistance of $R_{\text {via }}=15.9 \mathrm{~m} \Omega$ for a $20-\mu \mathrm{m}$ nominal diameter and 250- $\mu \mathrm{m}$-deep via, assuming a $\mathrm{Cu}$ resistivity of $\rho=2.0 \mu \Omega \cdot \mathrm{cm}$ (identical to the resistivity of the plated copper on the field).

Via chains with 2,10 , and 100 vias have been characterized electrically. The cumulative resistance versus the number of measured vias is plotted for chains with 2 vias, 10 vias, and 100 vias in Fig. 4. A perfect linear behavior is observed. The electrical lines connecting the vias are identical in all via chains (40 $\mu \mathrm{m}$ wide, $50 \mu \mathrm{m}$ long). The corresponding resistances of the front and back-side interconnect are $R_{\text {line }}=6.8 \mathrm{~m} \Omega$. This resistance is not negligible compared to resistance of a single via and contributes significantly to the total resistance of the chain. The resistance extracted from the slope of the line $(23.7 \mathrm{~m} \Omega)$ corresponds to the sum of the average resistance of one via and the average resistance of the top and bottom lines. In doing so, one can derive an average via resistance in the chain of $16.9 \mathrm{~m} \Omega$. This is fully consistent with the median resistance of Kelvin structures $(15.3 \mathrm{~m} \Omega)$. The resistance offset of the line corresponds to additional resistances from the admission line at the beginning 


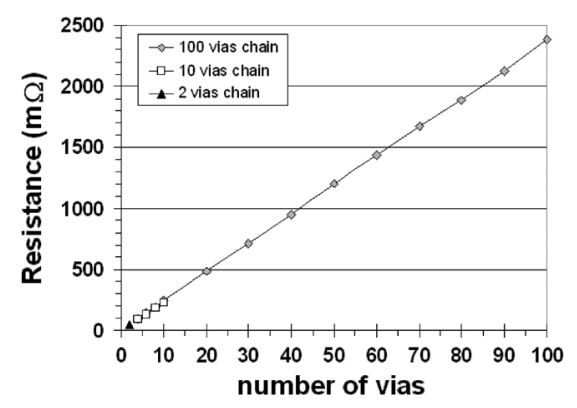

Fig. 4. Resistance versus number of vias for 2-, 10-, and 100-via chains with measurements at intermediate positions.

and the end of the line. It remains in the order of magnitude of an average line resistance.

\section{RF MEASUREMENTS}

\section{A. RF-Module Description and Measurements}

The RF module is comprised of RF copper lines with different lengths ( $40 \mu \mathrm{m}, 95 \mu \mathrm{m}, 170 \mu \mathrm{m}$, and $320 \mu \mathrm{m})$ in order to separate the electrical contribution of the line from the via RF behavior and to be able to extract the own resistance, inductance, and capacitance of the vias. The lines are $30 \mu \mathrm{m}$ wide and located on the back-side of the wafer. They are connected by two TSVs to the front-side from which the RF measurement is performed. Two designs have been used for these RF lines. The first set of lines has ground planes on the front-side only, while the second set of lines have both front-side and back-side ground planes, connected to each other by several identical TSVs with a diameter of $20 \mu \mathrm{m}$. In the latter case, the RF lines are also surrounded by ground planes at the back-side. The spacing between them and the transmission line is $29 \mu \mathrm{m}$. These two configurations are illustrated in Fig. 5. Top and back-side optical pictures of the micromachined coplanar waveguide+line of $95 \mu \mathrm{m}$ in the double-sided ground planes configuration are shown in Fig. 6. These two sets allow assessing the influence of ground planes on the back-side at RF frequencies. The RF measurements have been carried out on a dedicated RF probe station with a 2-port vector network analyzer with Cascade's dual infinity probes on a frequency range extending from $100 \mathrm{MHz}$ to $50 \mathrm{GHz}$. Special attention was paid to the calibration of the probes with a LRRM calibration protocol with a $50-\Omega$ calibration kit. All RF measurements have been de-embedded with the appropriate open-short corrections. It is, therefore, possible to compare the electrical results and extract information from the $S$-parameters.

\section{B. S-Parameters Analysis}

For the single and double ground plane configurations the signals are symmetrical $\left(S_{11}=S_{22}\right.$ and $\left.S_{12}=S_{21}\right)$ since there is no nonreciprocal component. For both configurations, the $S$-parameters $S_{11}$ and $S_{21}$ have been plotted in Fig. 7 for three different line lengths ( $40 \mu \mathrm{m}, 170 \mu \mathrm{m}$, and $320 \mu \mathrm{m})$.

One can observe that these lines exhibit a low reflection $\left(S_{11} \sim-20 \mathrm{~dB}\right)$ and high transmission in the low frequency range (100 MHz-1 GHz). This is the expected RF behavior in this frequency region and proves that the TSVs are functional within the evaluated CPW structure. The transmission $S_{21}$

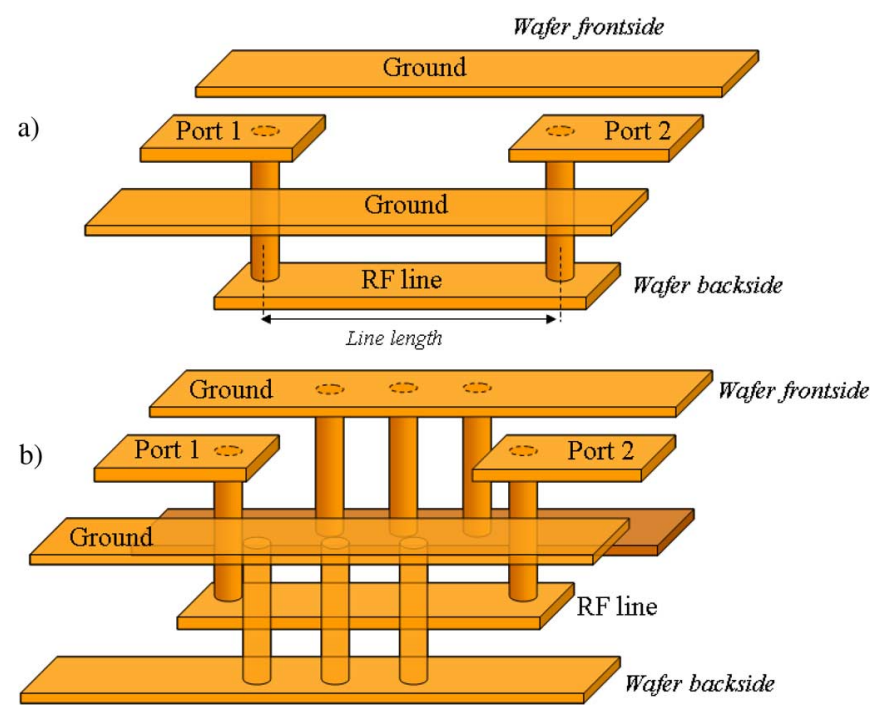

Fig. 5. Sketch of RF copper lines with TSVs (a) with ground planes at frontside only; (b) with ground planes at both the front and back- side.
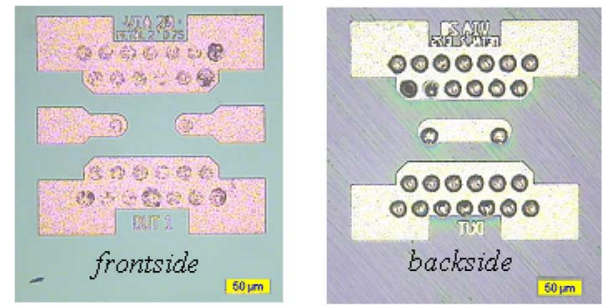

Fig. 6. Optical microscope images of a 95- $\mu \mathrm{m}$-long RF lines with TSVs and front and back-side ground planes connected with TSVs. Left: front-side view. Right: back-side view.
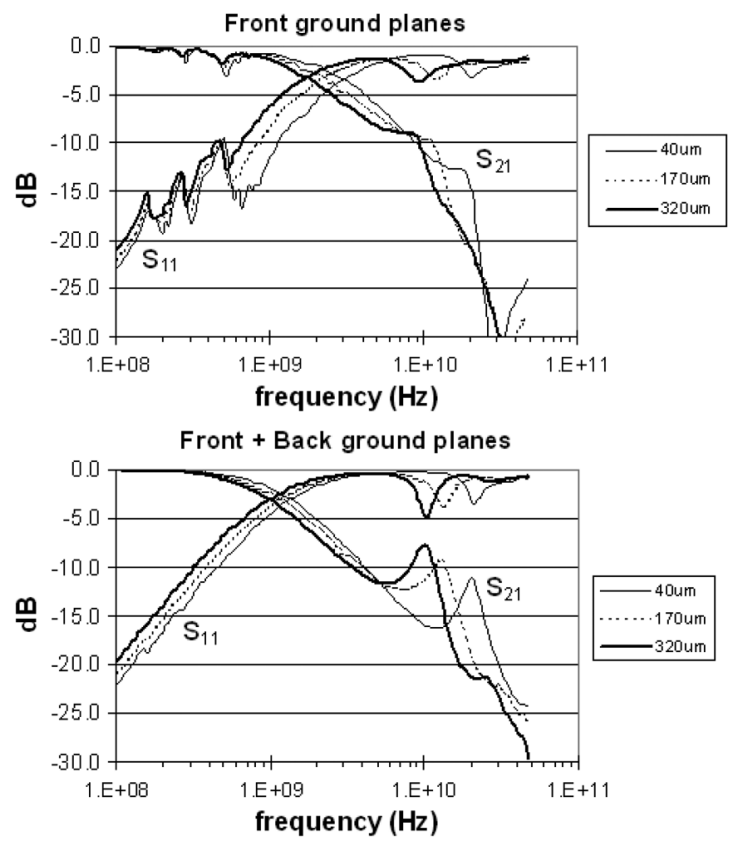

Fig. 7. $S$-parameters for different line lengths $(40 \mu \mathrm{m}, 170 \mu \mathrm{m}$, and $320 \mu \mathrm{m})$ with ground plane on front-side only and ground plane on front-side + back-side.

exhibits very low insertion losses at $100 \mathrm{MHz}(-0.15 \mathrm{~dB}$ for single ground planes, and $-0.04 \mathrm{~dB}$ for double ground planes) 


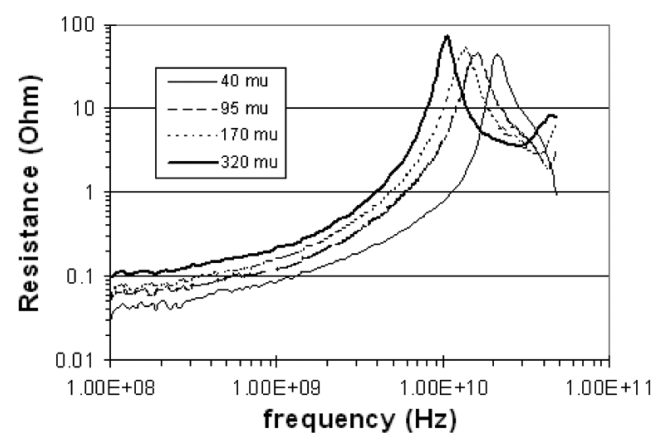

Fig. 8. Resistance $\mathrm{R}(\mathrm{Ohm})$ for $40-\mu \mathrm{m}, 95-\mu \mathrm{m}, 170-\mu \mathrm{m}$, and $320-\mu \mathrm{m}$ line lengths with ground planes on both front and back-side.

and starts decreasing beyond $1 \mathrm{GHz}$. The reflection increases continuously with frequency for the double ground plane configuration. Compared to the double-sided ground plane configuration, the presence of ripples is observed in the single sided ground planes case. These ripples appear reproducibly at identical frequencies for different line lengths, indicating that the ripples are design related. Such ripple can result from a parasitic coupling with the low resistive, floating substrate. In the double-sided ground planes case, the RF lines are surrounded with ground planes, which ensure a quasi transverse electromagnetic mode (TEM) propagation. Clear resonance peaks of the lines are observed above $10 \mathrm{GHz}$, whereas the resonance peaks are hardly distinguishable in the case of single plane grounding. These results clearly show the possibility to use double ground planes with TSVs connecting both sides in order to get clean signals with low losses. Being able to reduce the parasitic coupling is the first step towards 3D integration and $\mathrm{Si}$ interposer applications. The findings extend on the CPW results obtained in [6] which reports on T-resonators only. For the following electrical parameter discussion, we limit ourselves to the CPW double sided ground planes configuration.

\section{Resistance}

The total resistance of the vias and the line is derived from the real part of differential impedance defined as $Z_{\text {diff }}=Z_{0} *$ $\left(z_{11}-z_{12}-z_{21}+z_{22}\right)$, where $Z_{0}$ is the $50 \Omega$ characteristic impedance, and $z_{i j}$ the normalized impedance matrix elements extracted from the $S$-parameters. The resistance as function of frequency is plotted in Fig. 8 for different line lengths. As expected, the extracted resistance at $100 \mathrm{MHz}$ increases with the $\mathrm{Cu}$ line length, as is described in Table I and is consistent with the low loss transmission signal observed on the $S_{21}$ parameters. When the frequency increases, the RF-measured resistance increases due to the skin effect. The skin depth $\delta=\left(\rho / \pi \mathrm{f} \mu_{0}\right)^{1 / 2}$ in $\mathrm{Cu}$ at $100 \mathrm{MHz}$ is approximately $7 \mu \mathrm{m}$, implying that the skin effect already affects the effective resistance of $20-\mu \mathrm{m}$ vias + line. This could well explain the small difference between the $\mathrm{dc}$ and $100 \mathrm{MHz}$ resistance values. Above $10 \mathrm{GHz}$, the measured resistance deviates from the Eddy current behavior due to the intrinsic RF resonance of the CPW lines themselves due to the several $R, L$, and $C$ components in parallel and series (see later in the modelling, Section IV-F and in [6]). This is clearly observed in Fig. 8, where the energy dissipation at the resonance
TABLE I

COMPARISON OF THE LINE + VIAS RESISTANCE BETWEEN THE DC Calculated Value and the Measured Resistance at $100 \mathrm{MHz}$ FOR GROUNDED LINES

\begin{tabular}{|c|c|c|c|c|}
\hline Line length $(\boldsymbol{\mu m})$ & $\mathbf{4 0}$ & $\mathbf{9 5}$ & $\mathbf{1 7 0}$ & $\mathbf{3 2 0}$ \\
\hline $\begin{array}{c}\text { R extracted from } \\
\mathbf{D C}(\mathbf{m} \boldsymbol{\Omega})\end{array}$ & 37 & 45 & 55 & 75 \\
\hline $\begin{array}{c}\text { R extracted at 100 } \\
\mathbf{M H z}(\mathbf{m} \boldsymbol{\Omega})\end{array}$ & 39 & 53 & 63 & 95 \\
\hline
\end{tabular}

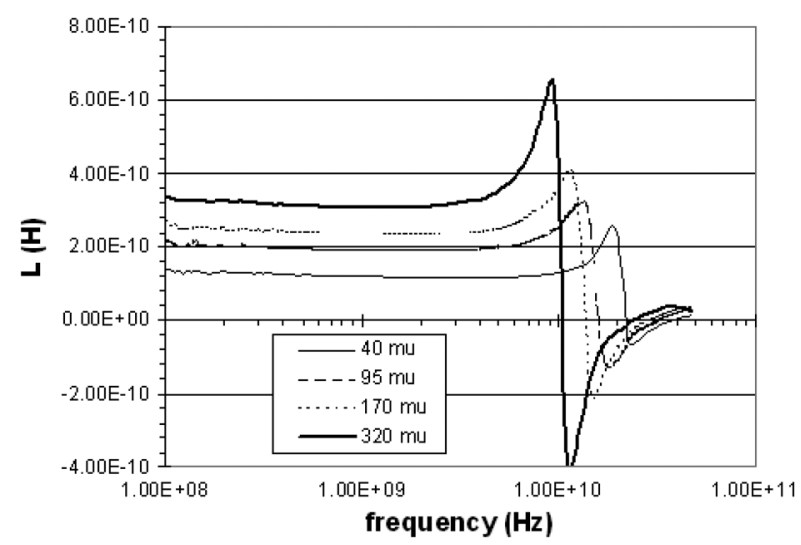

Fig. 9. Inductance $\mathrm{L}(\mathrm{H})$ for $40-\mu \mathrm{m}, 95-\mu \mathrm{m}, 170-\mu \mathrm{m}$, and $320-\mu \mathrm{m}$ length lines with both front-side and back-sides ground planes.

translates in a high resistive contribution to the total impedance. The longest lines show the smallest resonance frequency, following a $L C$-resonance mechanism.

\section{Inductance}

The series inductance written as $L=\operatorname{Im}\left(Z_{\text {diff }}\right) /(2 \pi \mathrm{f})$ of the line + vias is extracted from the imaginary part of the differential impedance and plotted in Fig. 9 for the different line lengths. The inductance linearly increases from 0.13 to $0.33 \mathrm{nH}$ for $40-\mu \mathrm{m}$ to $320-\mu \mathrm{m}$-long lines, with an inductance per meter of $7.1 \times 10^{-7} \mathrm{H} / \mathrm{m}$ for the line.

This value is fully consistent with standard values for CPWs found in literature for similar dimensions [5], [7], [16]. The extracted inductance of one via is $L_{\text {via }}=53 \mathrm{pH}$ at frequencies below $100 \mathrm{MHz}$. The main contribution to the total inductance depends on the length of the line. This inductance value is proportionally two times lower than inductance obtained for moderate aspect ratio vias described in [6] and [7], and 500-1000 times lower than wire bonding, making TSV very attractive for 3D integration. The resonance peaks fall at the resonance peaks already described in the resistance curves. The inductance decreases slightly from $100 \mathrm{MHz}$ to $\sim 3 \mathrm{GHz}$ due to the skin effect and is empirically modelled by a skin effect power law as in [6].

\section{E. Capacitance}

The total capacitance is extracted from the common mode admittance, $\operatorname{Im}\left(Y_{\text {com }}\right)$, defined as $Y_{\text {com }}=y 11+y 12+y 21+y 22$, where $y i j$ are the normalized admittance matrix elements extracted from the $S$-parameters. The capacitance $C=\operatorname{Im}\left(Y_{\text {com }}\right) /(2 \pi f)$ is plotted as a function of frequency in 


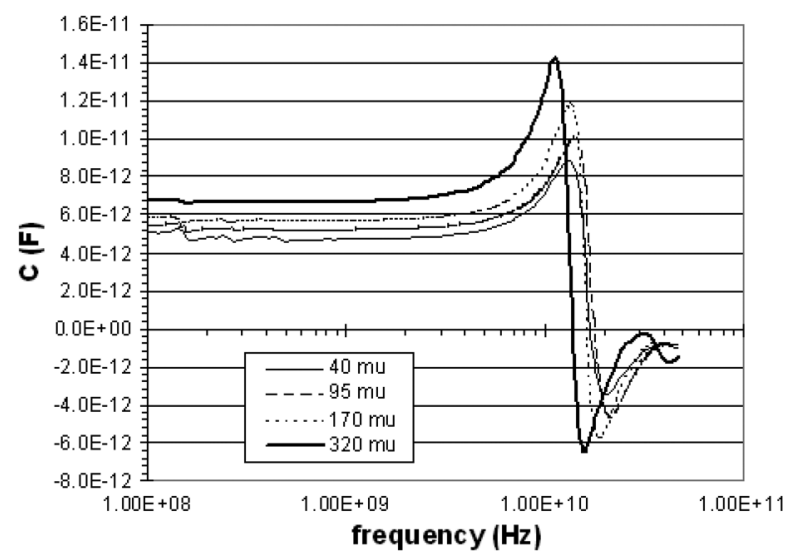

Fig. 10. Capacitance C (F) for 40- $\mu \mathrm{m}, 95-\mu \mathrm{m}, 170-\mu \mathrm{m}$, and 320- $\mu \mathrm{m}$ length lines with both front-side and back-side ground planes.

Fig. 10 for the different line lengths. The curves indicate that the via capacitance is dominating the total capacitance for the used line lengths. We extract an average capacitance per via of $2.4 \mathrm{pF}$, and a capacitance density of $4.6 \mathrm{pF} / \mathrm{mm}$ for the lines. This can be compared with the theoretical capacitance value based on the following calculations. The total area of the via outer surface is $A_{\text {via }}=20 \mu \mathrm{m} \times \pi \times 250 \mu \mathrm{m}$, and the dielectric constant of the SiN liner is $\varepsilon_{r} \sim 7.5$ and its thickness is $0.5 \mu \mathrm{m}$ and therefore: $C_{\text {via_theo }}=\varepsilon_{0} \varepsilon_{r} A_{\text {via }} / d_{\text {diel }}=2.1 \mathrm{pF}$. The measured value is higher than the theoretical one but can be explained by a nonideal bowed shape of the vias due to intrinsic limitation of the DRIE etching technique [18] and/or a slightly thinner insulation layer ( $\mathrm{SiN}$ ) in the middle of the via [5].

The nonnegligible capacitance value leads to a strong via coupling with the substrate at higher frequencies. For instance, the total capacitance of the 54 grounded vias of the $320 \mu \mathrm{m}$ double-grounded lines end up in a total capacitance of $54 \times$ $2.4=130 \mathrm{pF}$. As the substrate becomes strongly coupled to ground, the occurrence of parasitic resonances and/or ripples is prevented in these devices. If a lower capacitance is required, a silicon oxide insulation could easily replace the SiNx liner, reducing the capacitance by a factor of $\sim 1.8$.

\section{F. Modelling}

There is great interest trying to build an equivalent electrical model for the vias + line system that describes the full set of results with different dimensions in the microwave regime. A predictive analytical model would be very helpful to achieve a better understanding of 3D integration. Moreover, it would allow circuit optimization and make effective designs in the microwave regime. Obviously, a basic model with $R L C$ series is not sufficient to match the measured resonance frequencies, the capacitance and inductance levels independently, as has already been observed by others [19], [20]. In contrast a numerical simulation is very often to opaque and does not give a simple explanation for a certain behavior [7], [8]. Here, we propose an advanced analytical model for the lines+vias system, which is presented in Fig. 11.

It involves the inductance $L_{v}$, the capacitance $C_{v}$ and the resistance $R_{v}$ of the via and the inductance $L_{l}$, the capacitance $C_{v}$ and resistance $R_{l}$ of the line. The losses in the substrate are

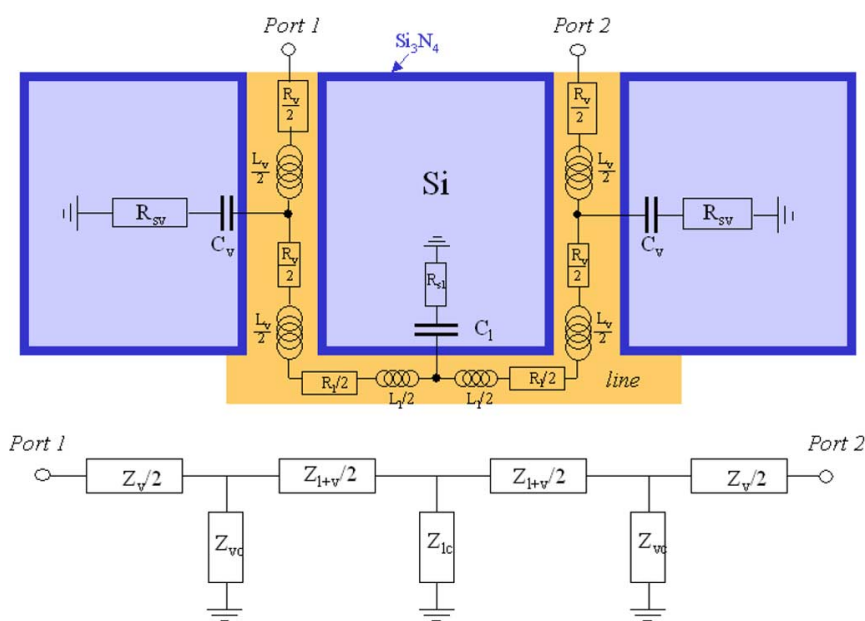

Fig. 11. Equivalent model for the vias + line circuit in RF measurements in a seven impedances electrical scheme.

taken into account as well by two resistances in series of the capacitances, $R_{s v}$ and $R_{s l}$, of the via and the line respectively. We assume here that the $\mathrm{Si}$ substrate is grounded at high frequency by means of the TSV ground planes. After two successive $\Pi-\mathrm{T}$ transformations of the electrical scheme, it is possible to derive analytical expressions for $R, L$, and $C$ for the vias+line system. There are eight parameters in this model: four for the via $\left(R_{v}\right.$, $L_{v}, R_{s v}$, and $\left.C_{v}\right)$ and four for the line $\left(R_{l}, L_{l}, R_{s l}\right.$, and $\left.C_{l}\right)$. Four of them $\left(R_{l}, R_{v}, C_{v}\right.$, and $\left.C_{l}\right)$ are known from the design layout and confirmed by dc measurements of the line: $L_{v}$ is not known a priori but must be constant whatever the line length, and $L_{l}$ should vary proportionally with the line length. The skin effect is taken into account in the vias and interconnects resistances $R_{v}$ and $R_{l}$. Thus, the only two fitting parameters are $R_{s v}$ and $R_{s l}$, which only depend on the damping of the system. One expects them to be in the same order of magnitude. The measured data for $R, L$, and $C$ with their corresponding modeled curves are plotted in Fig. 12 and Fig. 13 for the $40 \mu \mathrm{m}$ and $320-\mu \mathrm{m}$ grounded lines. The via parameters $R_{l}, R_{v}, C_{v}$, and $C_{l}$ derived from the geometrical layout and confirmed by the dc measurements have been used as input parameters. The model is fitting the $R, L$, and $C$ curves with a good accuracy below $5 \%$, especially at the lower frequency. The predicted resonance frequencies and the width of the resonance peaks are in very good agreement with the measurements. Using the same parameters for the $320-\mu \mathrm{m}$ case, the modeled capacitance is slightly lower than the measured value $(9 \%)$ which could be related due to a possible underestimation of the via capacitance for the longest lines (see Section IV-E). The inductance $L_{l}$ of the $320-\mu \mathrm{m}$ line leads to an 8 times higher inductance than the $40-\mu \mathrm{m}$ line and shows that also this parameter is in perfect agreement with the model. We derive a linear inductance of $5 * 10^{-7} \mathrm{H} / \mathrm{m}$ for the line that is consistent with the already discussed linear inductance. Similarly, the line capacitance $C_{l}$ is $\sim 8$ times higher for the $320 \mu \mathrm{m}$ than the $40-\mu \mathrm{m}$ line, which fits perfectly the scaling. All modeling parameters are summarized in Table II. Interestingly, this model predicts some additional resonance after the main resonance peak around $10 \mathrm{GHz}$ since second peaks and peak shoulders are observed in the model curves. The $L$ and $C$ 

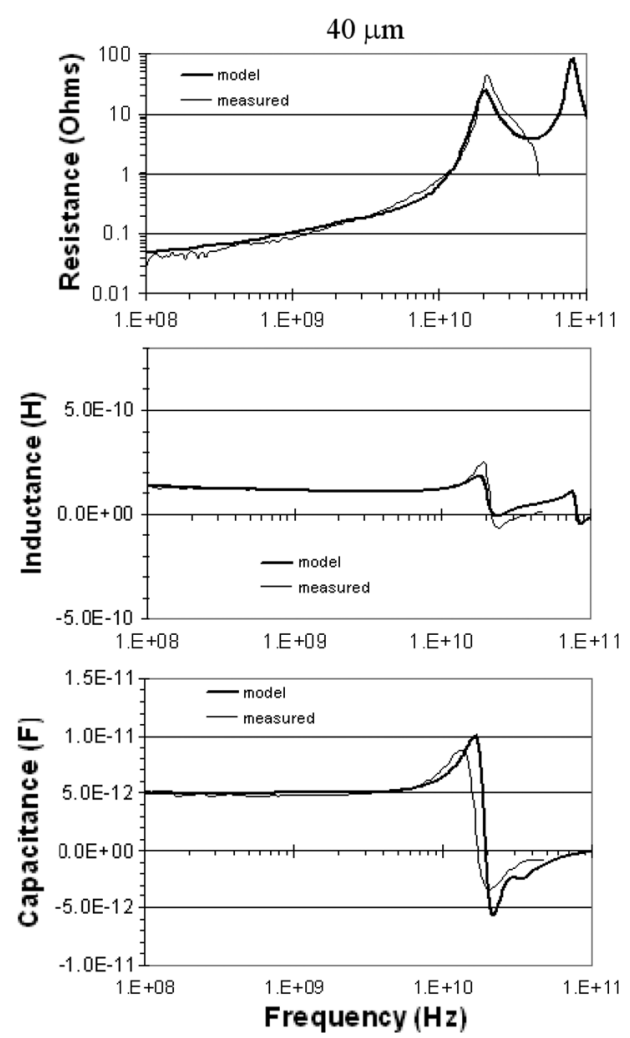

Fig. 12. $R, L$, and $C$ data curves versus fitted curves from the model for $40-\mu \mathrm{m}$ grounded lines.

measured curves suggest indeed the possibility of second resonances with a sharp slope of the curve, but the damping seems too high to have a clear picture of it. These possible extra resonance peaks must be investigated in more details by measuring at higher frequencies (e.g., $100 \mathrm{GHz}$ ) on a higher resistive substrate. Although many other models are possible, this refined model gives promising results with a minimum of fitting parameters since the only fitting parameters are the substrate losses resistances $R_{s v}$ and $R_{s l}$, which are close to each other $(0.8-6 \Omega)$. These values are relatively low and can be linked to the low intrinsic resistivity of the used wafer $(\sim 0.01 \Omega \cdot \mathrm{cm})$. This explains why the resonance peaks are relatively broad, and why secondary peaks are hardly observed. These results show that even with low resistivity silicon substrates as can be found in actual devices, the TSV behavior is well understood and can be modelled in the RF regime within good specifications.

\section{CONCLUSION}

In this work, we have used a "via-first" approach for making a RF silicon interposer. The through silicon vias were manufactured with micro-machining techniques and bottom-up electroplating. The dc resistance values match the theoretical expected values for TSVs with an aspect ratio of 12.5 and $250 \mu \mathrm{m}$ length. The electrical dc behavior has been confirmed in RF measurements where the resistance, the inductance and the capacitance values have been extracted. The need of front-side and back-side ground planes has been demonstrated because it
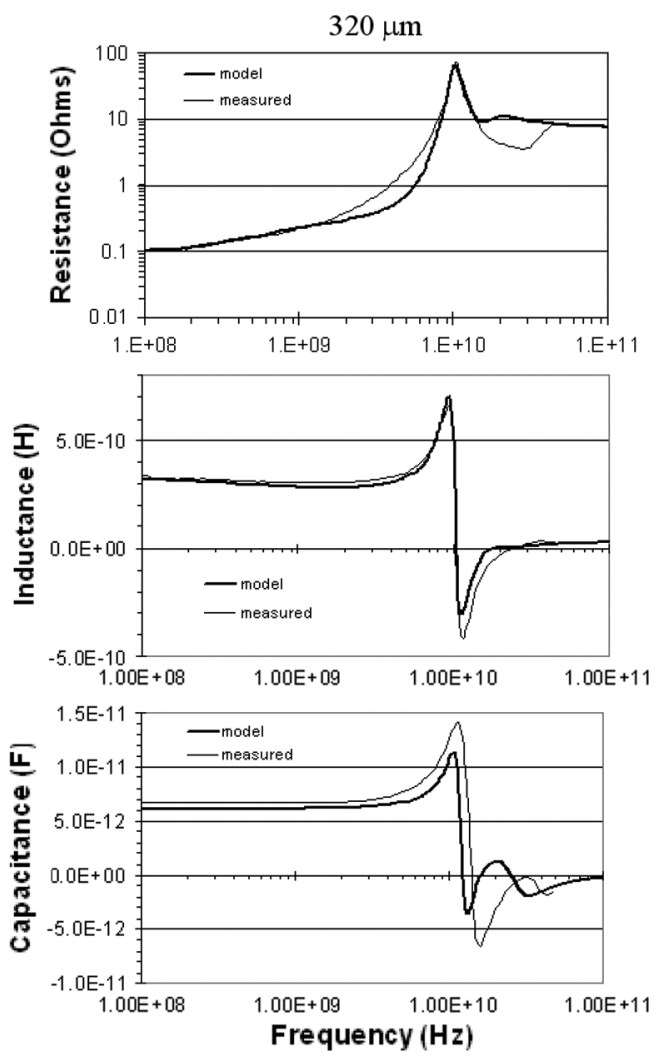

Fig. 13. $R, L$, and $C$ data curves versus fitted curves from the model for $320-\mu \mathrm{m}$ grounded lines.

TABLE II

MODEL PARAMETERS USED FOR MODELLING THE 40- $\mu \mathrm{m}$ AND 320- $\mu \mathrm{m}$ GROUNDED LINES. ONLY THE DAMPING PARAMETERS $R_{s v}$ AND $R_{s l}$ HaVe BeEN Used for the FIt. The Others Parameters are THE THEORETICAL VALUES EXPECTED FROM DESIGN

\begin{tabular}{|c|c|c|c|}
\hline \multicolumn{2}{|c|}{ Line lengths : } & $\mathbf{4 0} \boldsymbol{\mu} \mathbf{m}$ & $\mathbf{3 2 0} \boldsymbol{\mu m}$ \\
\hline \multirow{4}{*}{ vias } & $\mathrm{R}_{\mathrm{V}}(\Omega)$ & \multicolumn{2}{|c|}{0.015} \\
\cline { 2 - 4 } & $\mathrm{C}_{\mathrm{v}}(\mathrm{pF})$ & \multicolumn{2}{|c|}{2.4} \\
\cline { 2 - 4 } & $\mathrm{L}_{\mathrm{v}}(\mathrm{pH})$ & \multicolumn{2}{|c|}{50} \\
\cline { 2 - 4 } & $\boldsymbol{R}_{\boldsymbol{s} \boldsymbol{}}(\boldsymbol{\Omega})$ & 0.8 & 1 \\
\hline \multirow{4}{*}{ line } & $\mathrm{R}_{1}(\Omega)$ & 0.005 & 0.4 \\
\cline { 2 - 4 } & $\mathrm{C}_{1}(\mathrm{pF})$ & 0.16 & 1.28 \\
\cline { 2 - 4 } & $\mathrm{L}_{1}(\mathrm{pH})$ & 20 & 160 \\
\cline { 2 - 4 } & $\boldsymbol{R}_{\boldsymbol{s} \boldsymbol{l}}(\boldsymbol{\Omega})$ & 0.8 & 6 \\
\hline
\end{tabular}

prevents the occurrence of parasitic coupling RF signals. Functional CPWs on the back-side of the wafer have been achieved that was probed on the front-side of a low resistive silicon substrate. The low via capacitance $(2.4 \mathrm{pF})$ and low inductance $(53 \mathrm{pH})$ confirm the great potential of TSV for 3D packaging compared to wire bonding. An advanced electrical model has been successfully proposed and fits with good accuracy the total $R, L$, and $C$ curves of the vias + line system for two different line length as function of frequency. The resonance frequency can be predicted using only the dimensions of the system. The model is very powerful since it relies only on the theoretical design parameters of the system and two damping parameters whatever the line length. This model can be used as a guide for 3D integration modeling in the near future for system-in-package applications in the microwave regime. 


\section{ACKNOWLEDGMENT}

The authors would like to thank the collaborators from TU Delft: H. van Zeijl for the mask layout (dc and RF modules), Prof. P. M. Sarro for useful discussions on processing, and colleagues R. Pijper and L. Tiemeijer from NXP Research for RF characterization and data interpretation.

\section{REFERENCES}

[1] P. E. Garrou and E. Jan Vardaman, "Through silicon via technology, the ultimate market for 3D interconnect," in TechSearch Int., 2008.

[2] F. Roozeboom, M. A. Blauw, Y. Lamy, E. van Grunsven, W. Dekkers, J. F. Verhoeven, F. van den Heuvel, E. van der Drift, W. M. M. Kessels, and M. C. M. van de Sanden, Handbook of 3-D Integration: Technology and Application of 3 D Integrated Circuits, P. Garrou, C. Bower, and P. Ramm, Eds. Weinheim, Germany: Wiley-Verlag, 2008, pp. 47-91.

[3] K. Sakuma, P. S. Andry, C. K. Tsang, K. Sueoka, Y. Oyama, C. Patel, B. Dang, S. L. Wright, B. C. Webb, E. Sprogis, R. Polastre, R. Horton, and J. U. Knickerbocker, in ECTC, 2009, vol. 58, pp. 18-23.

[4] K. Fukushima, T. Yamada, Y. Kikuchi, H. Tanaka, and T. Koyanagi, in ECTC, 2007, vol. 57, pp. 836-841.

[5] J. H. Wu, J. Scholvin, and J. A. del Alamo, "A through-wafer interconnect in silicon for RFICs," IEEE Trans. Electron. Devices, vol. 51, no. 11, p. 1765, Nov. 2004.

[6] L. L. W. Leung and K. J. Chen, "Microwave characterization and modeling of high aspect ratio through silicon wafer interconnect vias in silicon substrates," IEEE Trans. Microwave Theory Tech., vol. 53, no. 8, p. 2472, Aug. 2005.

[7] L. Cadix, C. Bermond, C. Fuchs, A. Farcy, P. Leduc, L. DiCioccio, M. Assous, M. Rousseau, F. Lorut, L. L. Chapelon, B. Flecht, N. Sillon, and P. Ancey, "RF characterization and modelling of high density through silicon vias for 3D chip stacking," Microelec. Eng., vol. 87, pp. 491-495, 2010,

[8] R. Weerasekera, M. Grange, D. Pamunuwa, H. Tenhunen, and L.-R. Zheng, "Compact modeling of TSVs in 3D integrated circuits," in IEEE Int. Conf. 3D Syst. Integrat., 2009.

[9] I. U. Abhulimen, T. Lam, A. Kamto, S. Burkett, L. Schaper, and L. Cai, "Effect of via profile on copper seed layer deposition for electroplating," in Proc. IEEE Region 5 Conf., 2007.

[10] O. Lühn, C. van HooF, W. Ruythooren, and J.-P. Celis, Microelec. Eng., vol. 85, pp. 1947-1951, 2008.

[11] Z. Wang, L. Wang, N. T. Nguyen, W. A. H. Wien, H. Schellevis, P. M. Sarro, and J. N. Burghartz, "Silicon micromachining of high aspect ratio, high-density through-wafer electrical interconnects for 3-d multichip packaging," IEEE Trans. Adv. Packag., vol. 29, no. 3, p. 615, Aug. 2006.

[12] D. S. Tezcan, K. de Munck, N. Pham, O. Luhn, A. Aarts, P. de Moor, K. Baerts, and C. van Hoof, "Development of vertical and tapered via etch for 3D through wafer interconnect technology," in Electron. Packag. Tech. Conf., 2006.

[13] L. Wang, A. Nichelatti, H. Schellvis, C. de Boer, C. Visser, T. N. Nguyen, and P. M. Sarro, "High aspect ratio through-wafer-interconnections for 3-D Microsystems," in Proc. IEEE 16th Int. Microelecctromechan. Syst. Conf., Kyoto, Japan, Jan. 2003, pp. 634-637.

[14] L. J. van der Pauw, "A method of measuring the resistivity and hall coefficient on lamellae of arbitrary shape," Philips Tech. Rev., vol. 20, no. 8 , p. $220,1958 / 59$.

[15] T. A. Schreyer and K. C. Sraswat, "A two-dimensional analytical model of the cross-bridge Kelvin Resistor," IEEE Electron Device Lett., vol. 7, no. 12, pp. 661-663, Dec. 1986.

[16] N. Stavitsky, J. H. Klootwijk, H. W. van Zeijl, A. Y. Kovalgin, and R. A. M. Wolters, "A study of cross-bridge Kelvin resistor structures for reliable measurements of low contact resistances," in IEEE Conf. Microelectron. Test Structures, Edinburgh, U.K., Mar. 24-27, 2008, pp. 199-204.

[17] J. P. Michel, Y. Lamy, A. S. Royet, and B. Viala, "New RF magnetic stripe inductors with flanges based on exchange-coupled magnetic films," IEEE Trans. Magn., vol. 42, no. 10, p. 3368, Oct. 2006.

[18] M. Boufnichel, S. Aachboun, F. Grangeon, P. Lefaucheux, and P. Ranson, "Profile control of high aspect ratio trenches of silicon. I. Effect of process parameters on local bowing," J. Vac. Sci. Tech. B, vol. 20, no. 4, p. 1508, 2002.

[19] G. Elst, "Modeling and simulation of parasitic effects in stacked silicon," Mater. Res. Soc. Symp. Proc., vol. 970, p. 61, 2007.
[20] M. Jang, K. Y. Lee, C. H. Ryu, B. H. Cho, T. S. Oh, J. H. Kim, W. J. Lee, and J. Yu, "Fabrication and evaluation of 3D packages with Through Hole via," Mater. Res. Soc. Symp. Proc., vol. 970, p. 171, 2007.

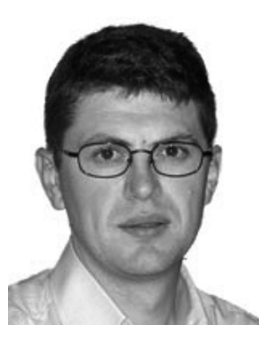

Yann P. R. Lamy was born in Le Creusot, France, in 1979. He received the engineering degree from the Ecole Supérieure de Physique et Chimie Industrielles of Paris and the M.S. degree in solid state physics from the University of Paris XI, in 2003, and the $\mathrm{Ph} . \mathrm{D}$. degree in physics in thin film magnetic materials for RF applications from the University of Limoges, in 2006.

From 2006 to 2008, he has worked as Research Scientist at NXP Semiconductors, Eindhoven, The Netherlands, on 3D integration, Through-Silicon Vias and integrated passive components. In 2009, he did some material research on phase change memory materials at NXP Eindhoven and Leuven. Since October 2009, he has joined CEA LETI Minatec in Grenoble, France, where he is a Research Scientist and Project Leader in 3D integration area in the Packaging and Integration Laboratory.

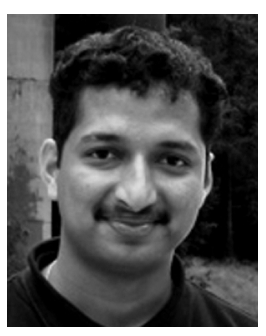

K. B. Jinesh received the M.S. degree in physics from Cochin University of Science and Technology (CUSAT), India, in 2000, and the Ph.D. degree in physics from Leiden University, The Netherlands, in 2006.

He was a researcher in Jawaharlal Nehru Center for Advanced Scientific Research (JNCASR) in India and Delft University of Technology in The Netherlands, in 2001 and 2002, respectively. From 2006 to 2008 he was a scientist in NXP Semiconductors, working in the field of atomic layer deposited high-k materials, especially, binary and ternary rare-earth metal oxides for high-density capacitor applications. Since 2009, he is working as a Researcher in IMEC Netherlands, in the field of sensors and actuators.

Fred Roozeboom received the M.Sc. degree in chemistry (cum laude) from the University Utrecht, Utrecht, The Netherlands, in 1976, and the Ph.D. degree in chemical engineering from Twente University, Twente, The Netherlands, in 1980.

He worked on zeolite catalysis with Exxon, Baton Rouge, LA (1980-1982) and Rotterdam, The Netherlands (1983). In, 1983 he joined Philips Research (since 2006: NXP Research) in Eindhoven, The Netherlands, where from 1997 to 2009 he lead a team working on passive and hetero-integration, in particular on viahole technology and 3D integration for application in system-inpackage products and on high-value passives in silicon for application in wireless communication, power management and digital signal processing. He authored or coauthored about 150 journal and conference publications, holds several patents, and is the editor or coeditor of 18 conference books on semiconductor processing. Since 2007 he is also a part-time Professor at the University of Technology, Eindhoven, The Netherlands, in the group Plasma and Material Processing. In 2009 he left NXP to join TNO Science and Industry, Eindhoven, The Netherlands as a Senior Technical Advisor.

Dirk J. Gravesteijn was born in Zaandam, The Netherlands, in 1953. He received the degree (cum laude) and the Ph.D. degree in chemistry from the University of Amsterdam, Amsterdam, The Netherlands.

He joined Philips Research Laboratories in Eindhoven, The Netherlands, where he started his work on organic polymeric conductors, and optical data storage (amongst other Phase Change recording). In 1987 he spent one year in DuPont Experimental Station, Wilmington, DE, where he worked on the physical mechanisms of optical data storage, after which he returned to Philips Research, Eindhoven, The Netherlands, where started to work on hetero-epitaxial films, in particular strained $\mathrm{Si} / \mathrm{SiGe}$ structures. From 1998 to 2001, he was responsible for the research on interconnect. In 2001, he joined Philips Research, Leuven, Belgium, also to be responsible for the interconnect activities. From 2005 he is involved in the Phase Change Memory work at the NXP-TSMC research center in Leuven. He is co-author on more than 100 papers in peer reviewed journals, and holds 14 patents. 
Dr. Gravesteijn has been active in organizing committees of several conferences (IITC, IEDM, VLSI technology), and is a member of the Steering Group technologies of CATRENE.

Wim F. A. Besling received the degree of chemical engineering, in 1993, and the Ph.D. degree on in situ Raman spectroscopy and laser-induced Fluorescence during laser-induced chemical vapor deposition, in 1999, both from Technische Universiteit, Delft, The Netherlands.

He joined Philips Research Laboratories in 1999 to work on diffusion barriers for $\mathrm{Cu}$ interconnects. From to 2000 to 2002 he has developed extensive exper- tise in atomic layer deposition of high-k dielectics at IMEC/Philips Research Leuven. From 2002 to 2007, he was part of the team research and development on advanced metallization at the alliance Philips Semiconductors and then NXP semiconductors in Crolles, France. From 2007, he is a project leader within System in Package group at NXP Semiconductors Research, Eindhoven, The Netherlands, aiming at the research and sevelopment of 3D interconnect (e.g., through silicon vias, wafer level packaging solutions), the integration of high density capacitors for RF decoupling and DC-DC conversion applications, and "More than Moore" microsystems and technology. He authored or co-authored many journal and conference publications, and holds several patents 